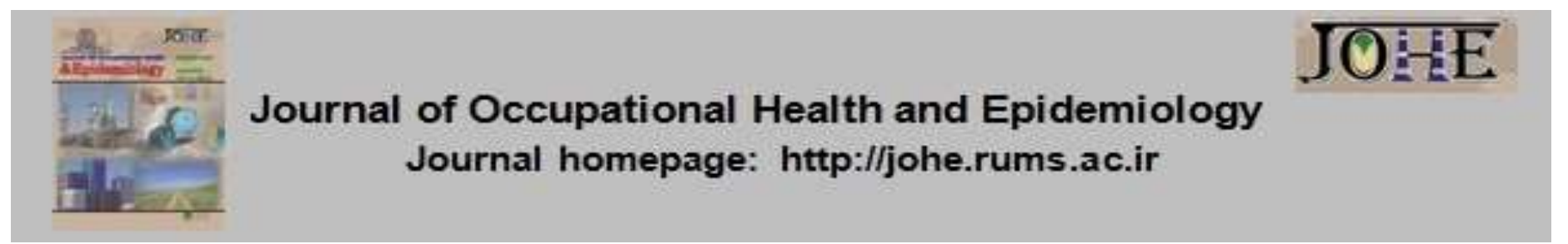

\title{
The Effect of Dialectical Behavior Therapy on Divorced Women's Psychosocial Adjustment and Cognitive Emotion Regulation
}

\author{
Hamideh Iri $^{1}$, Behnam Makvandi²*, Saeed Bakhtiarpour ${ }^{3}$, Fariba Hafezi ${ }^{3}$ \\ 1- PhD Student, Dept. of Health Psychology, Khorramshahr-Persian Gulf International Branch, Islamic Azad University, \\ Khorramshahr, Iran. \\ 2- Associate Prof., Dept. of Psychology, Ahvaz Branch, Islamic Azad University, Ahvaz, Iran. \\ 3- Assistant Prof., Dept. of Psychology, Ahvaz Branch, Islamic Azad University, Ahvaz, Iran.
}

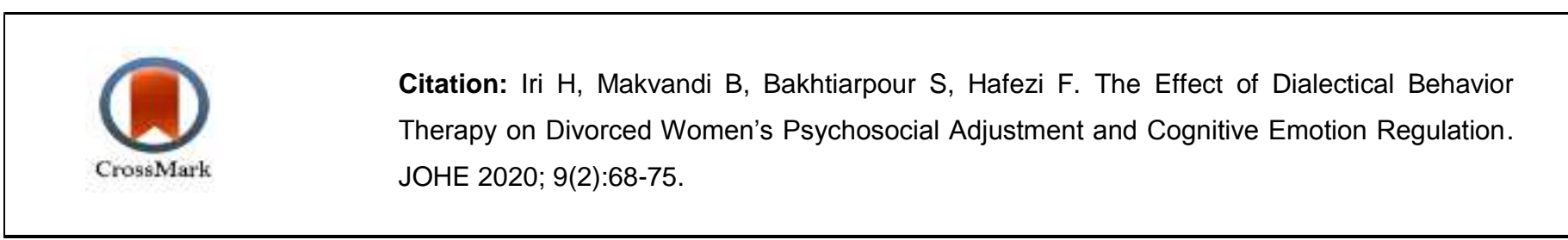

\section{Article Info}

* Corresponding author:

Behnam Makvandi,

E-mail:

makvandi203@gmail.com

\section{Article history}

Received: Jul 2020

Accepted: Oct 2020

$10.29252 /$ johe.9.2.68

Print ISSN: 2251-8096 Online ISSN: 2252-0902

Peer review under responsibility of Journal of Occupational Health and Epidemiology

\begin{abstract}
Background: Psychological pressures following divorce disturb women's psychosocial adaptation. The present study aimed to investigate the effect of dialectical behavior therapy (DBT) on psychosocial adjustment and cognitive emotion regulation in divorced women.

Materials and Methods: This study was conducted using a quasi-experimental method with a pretest-posttest design and a control group. The research population included all divorced women who had divorce-related psychological problems and referred to Tehran consultation centers in 2018. Using convenience sampling, 30 women willing to participate in the project were selected and randomly divided them into the experimental $(n=15)$ and control $(n=15)$ groups. The instruments used to collect the data were the Psychosocial Adjustment to Illness Scale and the Cognitive Emotion Regulation Questionnaire. The dialectical behavior therapy intervention was performed for the participants in the intervention group for ten 90-minute sessions.

Results: The mean scores of psychosocial adjustment and positive and negative emotion regulation in the intervention group were $64.33 \pm 4.32,28.00 \pm 7.26$, and $63.57 \pm 12.54$ respectively. DBT promoted psychosocial adjustment of the divorced women in the intervention group compared to the members of the control group $(\mathrm{P}=$ 0.001 ). Furthermore, this therapeutic technique caused a decrease in negative cognitive emotion regulation and an increase in positive cognitive emotion regulation among the divorced women in the intervention group $(P=0.001)$.

Conclusion: Given the findings of this study, it can be concluded that DBT is an effective technique to promote psychosocial adjustment and positive cognitive emotion regulation and also to reduce negative cognitive emotion regulation among divorced women.
\end{abstract}

Keywords: Dialectical Behavior Therapy, Social Adjustment, Women.

\section{Introduction}

Divorce represents a crisis affecting individuals' psychosocial and emotional health. It is associated with a lot of psychological pressures imposed on the involved spouses. Problems resulting from divorce vary depending on individuals' social, family, cultural, and even gender backgrounds [1, 2]. Divorced women who experience an emotional crisis have also lower social adjustment. Divorce has many negative psychological and social effects on women including the increased risk of mental and physical diseases, violence, and problems in expressing emotions. Moreover, divorce disturbs women's psychosocial adaptation [3]. The psychological pressures following divorce influence the level of adjustment to such pressures 
[4]. In contrast, an increase in the individual and social adjustment of divorced women would positively affect their acceptance of daily roles and responsibilities including employment, family, and others, as well as the development of their selfdependence [5]. Individuals sometimes suffer from emotional disorders due to some challenges faced in their life, which consequently threatens their emotional health and self-esteem [6, 7]. To this end, cognitive emotion regulation is mainly to support and shape a person's self-esteem, efficiency, and individuality by arousing positive emotions and avoiding negative emotions [8]. Divorced women will face many challenges in life if they have no proper cognitive emotion regulation as a result of their problems [9].

One of the main skills to be acquired is the ability to control one's emotions. If a person's cognitive emotion regulation does not function properly, the person will not be in a calm and stable state of emotional arousal and as such he/she cannot monitor and change his/her emotional experiences [10]. Cognitive emotion regulation plays a critical role in women's adjustment to stressful life events. The findings of previous studies have revealed that individuals' ability to effectively regulate their emotions is associated with significant impacts on their psychological well-being, interpersonal relationships, and mental health [11].

To solve and alleviate the aforementioned problems among this group of women, appropriate strategies should be adopted to improve their psychosocial adjustment and cognitive emotion regulation [12]. In recent years, the dialectical behavior therapy (DBT) approach has been used as one of the most common techniques for reducing the symptoms of mood, emotional, and anxiety disorders [13]. According to Martin et al. [14], DBT is directly involved in improving individuals' emotion regulation. There have also been some reports on the effectiveness of DBT and its group training in reducing self-harm behaviors, regulating emotions, and improving some mood and emotional disorders such as depression, anxiety, anger, emotional instability, and irritability. This technique highlights the role of emotion regulation and the goals of acquiring skills to encourage the cognitive control of maladaptive behavior patterns $[15,16]$. In terms of training, DBT supports the improvement of strong emotional control skills, the reduction of self-centered behaviors, and the promotion of interpersonal relationships to strengthen individuals' adaptability [17]. This intervention, as a holistic treatment technique, helps a person identify one's inner contradictions or the conflicts between himself/herself and the environment and achieve effective outcomes by combining and merging them [18]. DBT encompasses four main categories of mindfulness, emotion regulation, the effectiveness of interpersonal relationships, and ambiguity tolerance. This technique encourages individuals to adopt mindfulness in their daily activities. Training mindfulness skills in this intervention will help individuals to change their maladaptive behaviors, emotions, and thoughts as well as their interpersonal relationships in their life [13].

Divorced women deal with a large number of psychological, social, and emotional problems, all of which disturb the quality of their life. Proper training is required for this group to increase their psychosocial adjustment to life challenges and society and to help them to properly regulate their emotions. Accordingly, DBT can significantly contribute to improving psychosocial and emotional well-being of divorced women who perceive many psychosocial and emotional problems and suffer from lots of psychological pressures. Accordingly, the present study aimed to investigate the effect of DBT on divorced women's psychosocial adjustment and cognitive emotion regulation.

\section{Materials and Methods}

A quasi-experimental method with a pretestposttest design and a control group was employed to conduct this study. The research population included the divorced women who were affected by divorce-related psychological problems and referred to Tehran consultation centers in 2018. Via convenience sampling, we selected 30 women who were willing to participate in the project. Fifteen participants were included in each group using $G^{*}$ Power statistical software and with an effect size of 1.7, a test power of 0.95 , and $\alpha=0.05$ [19]. The inclusion criteria were getting a score lower than mean on the Psychosocial Adjustment to Illness Scale and the Cognitive Emotion Regulation Questionnaire, having psychopersonality disorders based on the questionnaire information, having at least a middle school literacy level, having married for at least a year, and divorced. The exclusion criteria were being absent at more than two treatment sessions, reluctance to continue the treatment process, having physical disorders, and taking medications. Dialectical behavior therapy training was performed by a family therapy therapist who had received specialized training and skills in this field. The therapeutic sessions were held one session per week. Two weeks after the completion of the training sessions, the post-test was administered 
to the participants in the intervention and control groups. The members of the control group did not receive any intervention. To comply with the requirement for ethical considerations, the researchers obtained written consent from all members of the two groups for their voluntary participation in the study.

The Psychosocial Adjustment to Illness Scale: This scale was developed by Derogatis [20] and contains 46 items and seven subscales (health care orientation (7 items), vocational environment (6 items), family environment (8 items), sexual relationships (6 items), extended family relationship (5 items), social environment ( 6 items), and psychosocial distress (7 items)). The items in the scale are scored based on a four-point Likert scale (0-3). The scores of all subscales were summed to determine the total score, which ranged from 0 to 138. A higher score on this scale indicates a lower psychosocial adjustment to illness. The construct validity of this scale using exploratory factor analysis indicated that the seven subscales together explain $63 \%$ of the total variance of the scale. Feghhi et al. [21] reported the reliability of the scale to be 0.91 . In the present study, the reliability coefficient of the scale was 0.85 based on Cronbach's alpha coefficient.

\section{The Cognitive Emotion Regulation} Questionnaire (CERQ): This questionnaire was developed by Garnefski and Kraaij [22]. It is a multi-dimensional questionnaire measuring cognitive coping strategies in the face of unfavorable incidents or situations. This questionnaire is a self-report tool with 36 items and assesses two emotional regulation subscales positive emotion regulation (acceptance, refocusing on planning, positive refocusing, positive reappraisal, and putting into perspective) and negative emotion regulation (self-blame, blaming others, rumination, and catastrophizing). Responses to the items in the questionnaire are scored on a five-point Likert scale ranging from 1 (almost) never) to 5 (almost) always). The positive emotion regulation subscale contains 20 items and the negative emotional regulation subscale contains 16 items. The total score is calculated as the sum of the scores obtained on the two subscales. Therefore, subscale scores can range from 4 to 20, with higher scores indicating a greater frequency of using a specific cognitive strategy. The range of scores for positive emotion regulation was between 16 and 80 and negative emotional regulation scores were between 20 and 100. Garnefski and Kraaij [22] reported the internal consistency of this questionnaire equal to 0.71 based on Cronbach's alpha coefficient. Besharat [23] assessed the construct validity by calculating the correlation coefficients between the scores of some participants in two shifts with an interval of two to four weeks. The corresponding values for the two subscales ranged from 0.42 to 0.57 at the level of 0.001 . The test-retest reliability of the subscales was reported as 0.75-0.81. Besodes, the reliability and validity of the questionnaire were reported to be at an acceptable level [23]. In this study, Cronbach's alpha was 0.79 for the questionnaire.

The participants in the intervention group received the dialectical behavioral therapy (DBT) intervention in ten 90-min sessions (one session per week). The content of the sessions is summarized in Table 1:

Table 1. Dialectical behavior therapy (DBT) sessions [24]

\begin{tabular}{cl}
\hline Sessions & \multicolumn{1}{c}{ Content of sessions } \\
\hline First & $\begin{array}{l}\text { Establishing rapport, attracting the group members' trust and involvement, introducing the members to } \\
\text { each other, reducing the group's stress, describing the rationale of the treatment, and making the } \\
\text { members familiar with the group work and its regulations. Reaching an agreement on treatment goals, } \\
\text { reviewing the members' feedback on the time and date of the meetings to increase training efficiency. }\end{array}$ \\
\hline Second & $\begin{array}{l}\text { Reviewing the assignments of the previous session. Discussing unpleasant events and experiences and } \\
\text { how they affected the emotions of the participants, examining techniques to control confusion, training } \\
\text { attention-disturbing techniques to manage confusion, presenting the practice of recording disturbing } \\
\text { situations and thoughts, and the effect of using attention-disturbing techniques in managing emotional } \\
\text { distress. }\end{array}$ \\
\hline Third & $\begin{array}{l}\text { Reviewing the assignments of the previous session. Examining other disturbing techniques, talking about } \\
\text { fundamental acceptance techniques, teaching how to use self-talks in fundamental acceptance, } \\
\text { presenting tasks to record the effect of using fundamental acceptance in managing emotional distress. }\end{array}$ \\
\hline Fourth & $\begin{array}{l}\text { Reviewing the assignments of the previous session. Investigating more advanced techniques to tolerate } \\
\text { emotional disorders such as setting rest time, living in the present, affirmative self-talk, and new coping } \\
\text { strategies, and presenting tasks to use several distress tolerance techniques depending on the } \\
\text { conditions and type of confusion and monitoring their effectiveness in managing emotional distress. }\end{array}$ \\
\hline Fifth $\quad \begin{array}{l}\text { Reviewing the assignments of the previous session. Discussing mindful attention and its effects on } \\
\text { managing distress, teaching mindful attention techniques such as the wise mind and intuition, presenting } \\
\text { tasks to use the taught techniques, and monitoring their effectiveness in managing emotional distress. }\end{array}$
\end{tabular}




\begin{tabular}{cl}
\hline Sixth & $\begin{array}{l}\text { Reviewing the assignments of the previous session. Conducting mindfulness meditation and receiving } \\
\text { feedback from the participants regarding their experienced feelings, teaching how to make decisions } \\
\text { based on mindful attention, including lack of judgment, fundamental acceptance, and mindful } \\
\text { communication, presenting tasks based on daily mindful attention, and recording variations under } \\
\text { distress conditions. }\end{array}$ \\
Seventh & $\begin{array}{l}\text { Reviewing the assignments of the previous session. Talking about emotions and their nature, discussing } \\
\text { different types of emotions and their various effects, examining techniques to reduce the effects of } \\
\text { negative emotions, e.g. increasing positive emotions, acting against the intense emotional desire, } \\
\text { presenting tasks on recording emotions, its effect on interpersonal relationships, and how to reduce } \\
\text { negative emotions. }\end{array}$ \\
\hline Eighth & $\begin{array}{l}\text { Reviewing the assignments of the previous session. Discussing effective and ineffective communication } \\
\text { skills, discussing the effects and consequences of ineffective communication, teaching the technique of } \\
\text { matching my orientations with the others', and the ratio of orientations and musts, presenting tasks to } \\
\text { monitor communication techniques and using them in interpersonal relationships }\end{array}$ \\
\hline Ninth $\quad \begin{array}{l}\text { Teaching other communication skills such as identifying orientations, moderating the intensity of } \\
\text { orientations, saying no, expressing a simple request, presenting tasks to use these techniques at the } \\
\text { right time and situation. }\end{array}$ \\
$\begin{array}{l}\text { Reviewing the assignments of the previous sessions and presenting the summary of the contents taught } \\
\text { in previous sessions, assessing the treatment progression and the achievement of the treatment goals, } \\
\text { surveying the participants' perspective of the future, the end of the treatment program, and the } \\
\text { administeration of post-test. }\end{array}$
\end{tabular}

The Kolmogorov- Smirnov test was used to examine the normality of distribution of the pre-test and post-test data. Besides, Levene's test was run to investigate the equality of variances. The collected data were analyzed using descriptive and inferential statistics, such as mean, standard deviation, multivariate analysis of covariance (MANCOVA), and analysis of covariance (ANCOVA) with SPSS software (version 24.0). Cronbach's alpha values were calculated to specify the reliability of the questionnaires.

\section{Results}

The mean and standard deviation (SD) of psychosocial adjustment post-test scores for the participants in the intervention and control groups were $64.33 \pm 4.32$ and $53.20 \pm 4.72$ respectively. The mean and SD of positive emotion regulation posttest scores in the intervention and control groups were reported as $28.00 \pm 7.26$ and $57.13 \pm 3.51$, respectivly. Meanwhile, the mean and SD of negative emotion regulation post-test scores in the intervention and control groups were respectively reported as $63.57 \pm 12.54$ and 43.10 \pm 13.25 . According to the results, the post-test scores of positive emotion regulation and negative emotion regulation were respectively increased and decreased in the intervention groups. Table 2 presents the mean and standard deviation (SD) of the pre-test and post-test scores of hypochondriasis and emotion regulation for the intervention and control groups.

Table 2. Mean and standard deviation of the variables in intervention and control groups in pre-test and post-test

\begin{tabular}{cccc}
\hline Variable & Group & Intervention group & Control group \\
\cline { 2 - 4 } & & $\mathbf{M} \pm \mathbf{S D}$ & $\mathbf{M} \pm \mathbf{S D}$ \\
\hline $\begin{array}{c}\text { Psychosocial } \\
\text { adjustment }\end{array}$ & Pre-test & $53.86 \pm 6.91$ & $52.92 \pm 4.81$ \\
\cline { 2 - 4 } $\begin{array}{c}\text { Positive emotion } \\
\text { regulation }\end{array}$ & Post-test & $64.33 \pm 4.32$ & $53.20 \pm 4.72$ \\
\cline { 2 - 4 } $\begin{array}{c}\text { Negative emotion } \\
\text { regulation }\end{array}$ & Pre-test & $57.17 \pm 3.60$ & $59.62 \pm 3.57$ \\
\cline { 2 - 4 } & Post-test & $28.00 \pm 7.26$ & $57.13 \pm 3.51$ \\
\hline
\end{tabular}

The null hypothesis indicating the scores for psychosocial adjustment, positive emotional regulation, and negative emotional regulation in the intervention and control groups had normal distributions. In other words, that the normality assumption of the distribution of post-test scores in both intervention and control groups was accepted (Table 3): 
Table 3. Results of the Kolmogorov-Smirnov test

\begin{tabular}{cccc}
\hline Normal distribution of & Gcores & Koups & Statistics \\
\cline { 2 - 4 } & & 0.07 & $\mathbf{P}$ \\
\hline $\begin{array}{c}\text { Psychosocial } \\
\text { adjustment }\end{array}$ & Experimental & 0.21 & 0.20 \\
\cline { 2 - 4 } $\begin{array}{c}\text { Positive emotion } \\
\text { regulation }\end{array}$ & Control & 0.16 & 0.08 \\
\cline { 2 - 4 } $\begin{array}{c}\text { Negative emotion } \\
\text { regulation }\end{array}$ & Experimental & 0.18 & 0.17 \\
\cline { 2 - 4 } & Control & 0.22 & 0.06 \\
\hline
\end{tabular}

The interaction $\mathrm{F}$-values of all the variables were not significant $(P>0.05)$; hence, the assumption of homogeneity of variance was accepted. Furthermore, the Levene's test results were not significant for psychosocial adjustment and positive/negative emotional regulation $(P>0.05)$; hence, the variances of the variables were not significant between the two intervention and control groups. Accordingly, the assumption of homogeneity of variance was confirmed. Moreover, the null hypothesis indicating the equivalence of the score variances was accepted. That is, the assumption of homogeneity of score variance in the two intervention and control groups was confirmed.

The results of the multivariate analysis of covariance (MANCOVA) showed a significant difference between the divorced women in the intervention and the control groups in terms of at least one of the dependent variables (namely psychosocial adjustment and positive/negative cognitive emotion regulation). As shown in Table 4 there was a significant difference between the divorced women in the two groups in terms of psychosocial adjustment, positive cognitive emotion regulation, and negative cognitive emotion regulation. That is, the analysis of the mean scores of the research variables indicated that this type of therapy promoted psychosocial adjustment and positive emotional regulation and decreased negative emotional regulation in the intervention group compared to the control group. The effect sizes were 0.77 for psychosocial adjustment, 0.82 for positive cognitive emotion regulation, and 0.80 for negative cognitive emotion regulation. In other words, $77 \%, 82 \%$, and $80 \%$ of the individual differences in the post-test scores for psychosocial adjustment, positive and negative emotion regulation of divorced women belonged to the impact of dialectical behavior therapy.

Table 4. Results of analysis of covariance (ANCOVA)

\begin{tabular}{|c|c|c|c|c|c|c|c|}
\hline $\begin{array}{c}\text { Dependent } \\
\text { variable }\end{array}$ & $\begin{array}{l}\text { Source of } \\
\text { Changes }\end{array}$ & SS & df & MS & $\mathbf{F}$ & $\mathbf{P}$ & $\eta 2$ \\
\hline \multirow{3}{*}{$\begin{array}{l}\text { Psychosocial } \\
\text { adjustment }\end{array}$} & Pre-test & 588.16 & 1 & 588.16 & 2.15 & 0.154 & 0.14 \\
\hline & Group & 8895.64 & 1 & 8895.64 & 39.18 & 0.001 & 0.77 \\
\hline & Error & 860.72 & 26 & 33.10 & & & \\
\hline \multirow{3}{*}{$\begin{array}{l}\text { Positive } \\
\text { emotion } \\
\text { regulation }\end{array}$} & Pre-test & 1252.49 & 1 & 1252.49 & 19.54 & 0.07 & 0.16 \\
\hline & Group & 8802.08 & 1 & 8802.08 & 48.88 & 0.001 & 0.82 \\
\hline & Error & 920.72 & 26 & 35.41 & & & \\
\hline \multirow{3}{*}{$\begin{array}{l}\text { Negative } \\
\text { emotion } \\
\text { regulation }\end{array}$} & Pre-test & 1222.77 & 1 & 1222.77 & 1.88 & 0.60 & 0.20 \\
\hline & Group & 7027.45 & 1 & 7027.45 & 333.51 & 0.001 & 0.80 \\
\hline & Error & 657.84 & 26 & 25.30 & & & \\
\hline
\end{tabular}

\section{Discussion}

The present study explored the effect of dialectical behavioral therapy (DBT) on psychosocial adjustment and cognitive emotion regulation in the divorced women living in Tehran. The results showed a significant difference between the intervention and control groups in terms of psychosocial adjustment, positive cognitive emotion regulation, and negative cognitive emotion regulation, as shown in the previous studies including Mami et al. [25], Ramaiya et al. [26], and
Jamilian et al. [27]. In other words, DBT promoted psychosocial adjustment and positive emotional regulation and decreased negative emotional regulation in the intervention group, compared to the control group.

Divorced women perceive many psychological burdens posed by social, psychological, and economic challenges. On the other hand, these women experience lower psychosocial adjustment due to the stress caused by living, family, and workplace problems for various reasons such as 
reduced income and declined standards of living [24]. In this study, DBT was found to improve psychosocial adjustment of this group of women. DBT intervention increased mental health in divorced women. Moreover, it encouraged these women to talk about unpleasant events and experiences and their impacts on their emotions and assisted them to exhibit a higher level of adaptability.

This technique also helped the divorced women learn how to promote their perceptions, feelings, and reactions to stress and social interactions and enhance their resilience and flexibility when dealing with social challenges by looking on the bright side and evaluating one's condition realistically and positively. This therapy changed the concentration of divorced women and made them adopt more positive attitudes and feelings and have a high awareness of their status by establishing their peace of mind in their individual and social activities [25]. The divorced women generally came up with more positive perceptions of themselves and the community. During the DBT sessions, reinforcement, feedback, and the performance of appropriate exercises helped the women to modify their misconceptions and form greater social interest, which in general had a significant impact on their psychosocial adjustment [26].

The divorced women attending the DBT treatment reported enhanced positive cognitive emotion regulation and reduced negative cognitive emotion regulation. Besides, the women had more control on their emotions and avoid overestimating them. They also avoided excessive replication of negative emotions. Therefore, they displayed more skills for monitoring their emotions, coping with demands, needs, and environmental pressures, and identifying personal abilities in addressing negative emotions [27]. The women undergoing DBT reported lower self-deprecation and showed more positive assessment in the face of pains, suffering, frustration, or failure, and reported that they were less strict on oneself in dealing with problems. Hence, this technique helped the women exhibit more positive emotions and maintain their health and emotional well-being by detecting problems and overcoming them, identifying their capabilities in difficulties, and having a positive concentration and regular planning [14]. This intervention modified the women's incompatible patterns of behaviors, emotions, and interpersonal relationships in life. It also provided the grounds for intelligent growth and fostered the divorced women's ability to delay unpleasant emotions, to effectively engage in or escape from negative emotions, and to wisely control their emotions.

Finally, DBT decreased the women's feelings of helplessness and non-adjustment with difficult conditions and made them more self-aware of their emotions. Besides, it helped the women develop a personal perspective toward positive emotions intertwined with self-awareness and mindfulness. Consequently, this group of women would better control their emotions and feel less frustrated and less self-deprecated with less unfavorable emotions. Using emotion regulation, this intervention made the divorced women more adjusted to the environment and empowered them in dealing with their problems. Thus, this technique helped the women to experience a more positive emotional balance.

Caution should be exercised in interpreting the findings of the present study suggesting that dialectical behavior therapy (DBT) increased sociopsychological adjustment and emotion regulation in the divorced women. Because the events in the therapy training sessions such as the therapist's behavior and interactions with the participants could have led to unwanted bias affecting the results. To confirm the effectiveness of this technique, a subsequent follow-up seems necessary.

One of the limitations of the present study was that the participants were heterogeneous in terms of demographic characteristics in the two intervention and control groups as well as controlling the social, economic, and family conditions affecting the divorced women. Given the critical role of DBT in promoting positive emotion regulation, reducing negative emotion regulation, and fostering psychosocial adjustment, authorities are recommended to hold training workshops for this group of women.

\section{Conclusion}

DBT leads to emotional cohesion, adaptive behavior adjustment, positive and negative emotion assessment, and improves emotional well-being and psychosocial adjustment of divorced women. Consequently, DBT can be effective in promoting positive emotion regulation, decreasing negative emotion regulation, and improving psychosocial adjustment among the same group of women.

\section{Acknowledgement}

This article was extracted from a Ph.D. dissertation by Hamideh Iri in the Department of Health Psychology, Khorramshahr-Persian Gulf International Branch, Islamic Azad University, 
Khorramshahr, Iran (code: 84520709981004). The authors wish to appreciate all the individuals who participated in the study.

\section{Conflict of interest: None declared.}

\section{References}

1. Pirak A, Negarandeh R, Khakbazan Z. PostDivorce Regret among Iranian Women: A Qualitative Study. Int J Community Based Nurs Midwifery 2019; 7(1):75-86.

2. Wolchik SA, Tein JY, Sandler IN, Kim HJ. Developmental cascade models of a parentingfocused program for divorced families on mental health problems and substance use in emerging adulthood. Dev Psychopathol 2016; 28(3):86988.

3. Jalili L, Najar S, Nezamivand-Chegini S, Yaralizadeh M. The Relationship between Factors Related to Divorce Request and Mental Health among Divorce Applicant Women Referred to Legal Medicine Organization in Ahvaz, Iran. J Family Reprod Health 2017; 11(3):128-37.

4. Rosenström $T$, Fawcett TW, Higginson AD, Metsä-Simola N, Hagen EH, Houston Al, et al. Adaptive and non-adaptive models of depression: A comparison using register data on antidepressant medication during divorce. PLoS One 2017; 12(6):e0179495.

5. Rognmo K, Torvik FA, Idstad M, Tambs K. More mental health problems after divorce in couples with high pre-divorce alcohol consumption than in other divorced couples: results from the HUNT-study. BMC Public Health 2013; 13:852.

6. Okur Güney ZE, Sattel $H$, Witthöft $M$, Henningsen $P$. Emotion regulation in patients with somatic symptom and related disorders: A systematic review. PLoS One 2019; 14(6):e0217277.

7. Hazrati M, Hamid TA, Ibrahim R, Hassan SA, Sharif F, Bagheri Z. The Effect of Emotional Focused Intervention on Spousal Emotional Abuse and Marital Satisfaction among Elderly Married Couples: A Randomized Controlled Trial. Int $\mathrm{J}$ Community Based Nurs Midwifery 2017; 5(4):329-34.

8. Wilms R, Lanwehr R, Kastenmüller A. Emotion Regulation in Everyday Life: The Role of Goals and Situational Factors. Front Psychol 2020; 11:877.

9. Ghorbani-Amir HA, Moradi O, Arefi M, Ahmadian H. The Effectiveness of Cognitive Behavioral Components Training on Emotional Cognitive Adjustment, Resilience and SelfControlling Strategies among Divorced Women. Salamat ljtimai (Community Health) 2020; 7(2):166-74.

10. Karimi N, Naziry G. Predicting the rate of cigarette smoking based on resilience and cognitive emotion regulation in the non-clinical population of Shiraz, Iran, 2016. Journal of
Occupational Health and Epidemiology 2018; 7(4):213-21.

11. Li L, Zhu X, Yang Y, He J, Yi J, Wang Y, et al. Cognitive emotion regulation: characteristics and effect on quality of life in women with breast cancer. Health Qual Life Outcomes 2015; 13:51.

12. Akhlaghi Yazdi Nejad F, Hossein Sabet F, Borjali A. Effectiveness of emotion regulation training on increasing self-efficacy and wellbeing in drug-dependent individuals. Journal of Occupational Health and Epidemiology 2017; 6(1):9-16.

13. Fassbinder E, Schweiger U, Martius D, Brandde Wilde O, Arntz A. Emotion Regulation in Schema Therapy and Dialectical Behavior Therapy. Front Psychol 2016; 7:1373.

14. Martin CG, Roos LE, Zalewski M, Cummins N. A Dialectical Behavior Therapy Skills Group Case Study on Mothers with Severe Emotion Dysregulation. Cogn Behav Pract 2017; 24(4):405-15.

15. Neacsiu AD, Tkachuck MA. Dialectical behavior therapy skills use and emotion dysregulation in personality disorders and psychopathy: a community self-report study. Borderline Personal Disord Emot Dysregul 2016; 3:6.

16. Chapman AL. Dialectical behavior therapy: current indications and unique elements. Psychiatry (Edgmont) 2006; 3(9):62-8.

17. Goodman M, Carpenter D, Tang CY, Goldstein $\mathrm{KE}$, Avedon J, Fernandez N, et al. Dialectical behavior therapy alters emotion regulation and amygdala activity in patients with borderline personality disorder. J Psychiatr Res 2014; 57:108-16.

18. Zamani N, Habibi M, Darvishi M. To Compare the Effectiveness of Dialectical Behavior Therapy and Cognitive Behavioral Group Therapy in Reducing Depression in Mothers of Children with Disabilities. Journal of Arak University of Medical Sciences 2015; 18(1):3242.

19. Afroundeh R, Saidzanozi R. Comparison of the effect of Pilates and traditional corrective exercises on lumbar lordosis in female students. Scientific Journal of Rehabilitation Medicine 2017; 6(3):84-94.

20. Derogatis LR. The psychosocial adjustment to illness scale (PAIS). J Psychosom Res 1986; 30(1):77-91.

21. Feghhi H, Saadatjoo SA, Dastjerdi R, Kalantari $S$, Alidousti $M$. The effect of a training program based on Roy's adaptation model on psychosocial adaptation in patients with type II diabetes in Birjand, Iran. Journal of Diabetes Nursing 2016; 4(2):8-24.

22. Garnefski N, Kraaij V. Cognitive emotion regulation questionnaire - development of a short 18-item version (CERQ-short). Pers Individ Dif 2006; 41(6):1045-53.

23. Besharat MA. Cognitive Emotion Regulation Questionnaire: Instruction and Scoring. Journal 
of Developmental Psychology 2017; 13(50):221-3.

24. Linehan M. Cognitive-Behavioral Treatment of Borderline Personality Disorder. Illustrated Ed. New York, United States: Guilford Press, 1993.

25. Mami S, Ebrahimian S, Soltany S. Effectiveness of Dialectic Behavioral Therapy on Depression, Anxiety and Stress in Anorexia Nervosa Disorder: Four Case Study. Studies in Medical Sciences 2016; 27(5):384-92.

26. Ramaiya MK, McLean C, Regmi U, Fiorillo D,
Robins CJ, Kohrt BA. A dialectical behavior therapy skills intervention for women with suicidal behaviors in rural Nepal: A single-case experimental design series. J Clin Psychol 2018; 74(7):1071-91.

27. Jamilian HR, Malekirad AA, Farhadi M, Habibi M, Zamani N. Effectiveness of group dialectical behavior therapy (based on core distress tolerance and emotion regulation components) one expulsive anger and impulsive behaviors. Glob J Health Sci 2014; 6(7 Spec No):116-23. 